\title{
Studies on Feasibility of Reverse Osmosis (Membrane) Technology for Treatment of Tannery Wastewater
}

\author{
Kuppusamy Ranganathan, Shreedevi D. Kabadgi \\ Central Pollution Control Board, Zonal Office (South), Shivanagar, Bangalore, India. \\ Email: rangacpcb@yahoo.com, skabadgi@gmail.com
}

Received October 12 $2^{\text {th }}, 2010$; November 19 $9^{\text {th }}, 2010$; December $28^{\text {th }}, 2010$.

\begin{abstract}
Tanneries reusing wastewater by combination of conventional and advanced Reverse Osmosis (RO) treatment technologies were assessed for technical and economic viabilities. Conventional treatment methods such as neutralization, clari-flocculation and biological processes are followed to clean the effluents before feeding to RO membrane modules. The characteristics of untreated composite effluents such as $\mathrm{pH}$, biochemical oxygen demand (BOD), chemical oxygen demand (COD), total suspended solids (TSS), total dissolved solids (TDS), and total chromium were in the range of 4.00-4.60, 680-3600 mg/L, 1698-7546 mg/L, 980-1480 mg/L, 4200-14500 mg/L, and 26.4-190 mg/L, respectively. Inorganic ions like $\mathrm{Ca}^{2+}, \mathrm{Na}^{+}, \mathrm{Cl}^{-}$and $\mathrm{SO}_{4}{ }^{2-}$ were found more in the wastewaters. Conventional treatments significantly removed the organic pollutants however failed to remove dissolved inorganic salts. Membrane technology removed the salts as well as remaining organic pollutants and the product water is reused in the process. The studied tanneries (5 numbers) have achieved $93-98 \%, 92-99 \%$ and $91-96 \%$ removal of TDS, sodium and chloride, respectively. Seventy to eighty five percentage of wastewater was recovered and recycled in the industrial processes. The rejects are subject to either solar evaporation system or Multiple Effect Evaporation (MEE) technology. The resulting salts are collected in polythene bags and disposed into scientifically managed secured land fill (SLF) site. The cost of wastewater treatment for operation and maintenances of RO including the pre-treatments (conventional methods) is INR 100-110 $\mathrm{m}^{-3}$.
\end{abstract}

Keywords: Reverse Osmosis (RO), Membrane Technology, Recycling, Tannery Waste Water

\section{Introduction}

Processing of hides and skins of animals are carried out in tanneries for making durable and flexible leather material which is used for manufacturing of shoes, overwear goods, bags etc. Tannery, one of the ancient craft industries, significant in terms of Indian exports and employment opportunity for the people of economically weak population causes alarming levels of environmental pollution by various operations [1,2] such as soaking, liming, de-liming, pickling, tanning and finishing. During the tanning processes about $300 \mathrm{~kg}$ of chemicals are added per ton of hides and they generate large volume of effluents generally in the range of $34-56 \mathrm{~m}^{3}$ per ton of hides with high total dissolved solids, organic pollutants and toxic chemicals. In India there are about 3,000 tanneries with a total processing capacity of $700 \mathrm{k}$ Tons of hides and skins per annum. They are categorized as large, medium and small tanneries depending on their produc- tion capacity. Most of the small tanneries cater to the local market, while the large tanneries are primarily export oriented. Vellore District of Tamil Nadu in India has clusters of tanning units at Vaniambadi, Ambur, Ranipet and Vellore. There are about 600 tanneries in that area and are spread over various clusters in the area of 1650 $\mathrm{km}^{2}$. The tanning activities have been carried out in that area for more than 100 years with out any pollution control equipments and the treatment concept has emerged only after 1980 's.

The generated effluents were discharged into the river Palar through unlined channel that resulted in surface as well as ground water pollution [3]. The river Palar is a seasonal one and that carries water for a period of three to four months in a year but that too due to failure of monsoon in the last few years and construction of many reservoirs in the upstream of the river there is no flow in the river. Due to shortage of rainfall and continuous 
drawing of ground water for agricultural and industrial use ground water table decreased. The industrial discharges flow for $3 \mathrm{~km}$ and after disappear due to sandy and loamy soil texture and the percolation of wastewater has resulted in pollution. The river bed allows percolation of the effluent resulting in increase of total dissolved solids to the tune of $8000 \mathrm{mg} / \mathrm{L}$ in the ground water over the period of last few decades [4]. The mass transport model in the Upper Palar basin has predicted the migration of ground water due to discharge of tannery effluents on the ground and in the Palar River [5]. The multifold increase of dissolved solids level in ground water warrants the need to look into the operation status of the effluent treatment plant and up gradation of the technology of treatment with possible exploration of introduction of advanced technologies in order to recycle the wastewater or to dispose off in an environmentally sustainable way.

The conventional treatment methods such as chemical flocculation and biological processes like Up-Flow Anaerobic Sludge Blanket (UASB) and Activated Sludge Process (ASP), are effective in removal of organic pollutants. The biological processes, UASB and ASP were compared to find efficiency and found that the ASP is superior [6]. UASB has been proved to be a gas generating process and the high contents of sulphide being one of the limiting factors and to overcome that attempts were also made [7]. However those processes are not competent in reduction of total dissolved in-organics (TDS). Hence many attempts were made to attain zero-discharge to save the environment. As the tannery wastewater consists of nutrients, it has been attempted for composting with cow manure and wheat straw for 90 days. The compost characteristics indicated that it was mature but the germination index for cress of less than $50 \%$ suggested pytotoxins are remaining in the compost [8]. Membrane technologies are other recent advanced methods to solve the problem of dissolved solids in the effluents. Pilot studies have been carried out for removal of chromium from tannery wastewaters using RO membrane system and found high concentration of $\mathrm{NaCl}$ affected chromium separation as well as percent recovery of permeate $[9,10]$. In the present study, some tanneries located in Vellore District, Tamil Nadu, India which have installed Reverse Osmosis membrane process are studied to evaluate their performances and also the cost analysis.

\section{Materials and Methods}

\subsection{Study Area}

Five tanneries operating Reverse Osmosis membrane technology namely M/s Eastern Chrome Tanning Corporation, M/s T. Abdul Wahid Company, Unit-C, M/s
Jaibharath Tanners, M/s N.M.Zackariah \& Co, M/s Habeeb Taj Tanning Company located at Ambur and Gudiyattam in Vellore districts of Tamil Nadu were monitored and information such as, production capacity, raw materials, water consumption, wastewater generation and available treatment technologies were collected. Generally, three types of operation such as raw to finish, raw to semi-finish and semi-finish to finish are followed in that area. In raw to semi-finish the waste water streams are segregated into three channels i.e. high TDS soaking wastewater, high BOD process effluent and highly toxic chromium wastes. The general processes followed and wastewater generations are depicted in the following paragraph:

\subsection{Tanning Processes Followed in the Studied Area and Wastewater Generation}

Hides and skins after stripping in the slaughterhouse are immediately preserved by applying $\mathrm{NaCl}(1: 3$ salt and skin weight ratio) and are brought to the tanneries for making leather. Initially salt is removed by manual or mechanical desalting and the hides are soaked in tank filled with water for overnight and also one hour soaking is carried out at last in fresh water. Soaking removes the salt with generation of about $12-15 \mathrm{~L} / \mathrm{kg}$ wastewater with high TDS in the range of $21000-57000 \mathrm{mg} / \mathrm{L}$ [11] and these effluents are subjected to solar evaporation. The solar evaporation ponds are concrete cemented by providing HDPE liner to avoid ground water percolation. As a next step to remove hair, flesh and unwanted organics, the hide is soaked in a suspension of lime (7\%) and sodium sulfide $(2.5 \%)$ overnight and subject to de-hairing and de-fleshing. The quantity of effluent generated is 5 $\mathrm{L} / \mathrm{kg}$ with high calcium, sodium, sulfide and organic pollutants. The liming process is followed by ammonium salt pickling overnight for removal of impregnated lime in the pores of hides. Then acid-pickling using sulphuric acid or formic acid is used to bring down the $\mathrm{pH}$ to 2-4 to avoid biological affect and good tanning.

Either chrome or vegetable tanning is followed in a rotating drum batch reactor. Chromic acid solution of about $7 \%$ is used for tanning for about 8 hours. $20-40 \%$ of the used chromium salts are let out into the wastewaters. The batch process solutions are separated and subject to chrome recovery. Vegetable tanning takes 8 days for tanning. Several washings are carried out to remove traces of $\mathrm{Cr}$ and about $20 \mathrm{~m}^{3}$ of wastewater per ton of hide/skins are generated. Trimming and Plating are followed which are dry processes and only solid wastes are generated which are used for manufacturing of many products. Dyeing and setting are also followed in the finishing stage. Dyeing also generates wastewater from dye-bath and washing solutions. The final product is $50 \%$ 
of the raw hide used and the rests are disposed as solid waste and liquid effluent. Total wastewater generation is $40-45 \mathrm{~m}^{3} / \mathrm{t}$ of product. The wastewaters generated are segregated as High TDS soaking wastewater, Chromium containing tanning wastewater and other high BOD organic and inorganic washing wastewater. The soaking wastewater, which consists of salt, sent for solar evaporation. Chromium spent is treated for recovering chromium salts [12]. One kilo liter of the spent chromium solution is mixed with $3.3 \mathrm{~kg}$ of magnesium oxide and the recovered salt is about $5.5 \mathrm{~kg}$.

$$
\mathrm{Cr}_{2}\left(\mathrm{SO}_{4}\right)_{3}+3 \mathrm{MgO}+3 \mathrm{H}_{2} \mathrm{O} \rightarrow 3 \mathrm{Mg} \mathrm{SO}_{4}+2 \mathrm{Cr}(\mathrm{OH})_{3} \downarrow
$$

\subsection{Tanneries Studied for Performances in Vellore District, Tamil Nadu}

\subsubsection{M/s Eastern Chrome Tanning Corporation, Ambur}

Eastern Chrome Tanning Corporation with production capacity of 4.3 tons per day deals with semi finishing to finishing. The total quantity of wastewater $130 \mathrm{~m}^{3} / \mathrm{d}$ from the process are passed through a bar screen to remove coarse particles and collected in a collection tank. The effluent pumped to a clari-flocculator with required dosing of lime and polyelectrolyte and allowed for settling of solids. The effluent is subjected to two stage biological oxidation using diffused aeration in aeration tank-I and aeration tank-II followed by clarifiers. Again the effluent is polished with lime/soda and Poly Aluminum Chloride (PAC). The sludge generated are dried on sludge drying bed and collected in polythene bags.

Before feeding into RO membrane cartridge, suspended solids, Fe and $\mathrm{Mn}$ are removed by sand and ion filters to protect the membrane. The out let reject of 21.6 $\mathrm{m}^{3} / \mathrm{d}$ and permeates are collected in the ratio of $1: 3$, respectively. The effluents collected from the different treatment stages were subject to analysis.

\subsubsection{M/s T. Abdul Wahid Company, Unit-C, Ambur}

$\mathrm{M} / \mathrm{s}$ T. Abdul Wahid Company Unit-C which deals with semi-finishing and finishing of tanned leather was monitored. The production capacity of the unit is about $2.4 \mathrm{t} / \mathrm{d}$. Trimming, plating, designing, dyeing etc are the processes carried out in the Unit. Wastewater of about 35 $\mathrm{m}^{3} / \mathrm{d}$ is generated and it contains organic and inorganic pollutants. The dye bath colored effluent is also mixed with the effluent streams. The effluent treatment plant consists of Primary (Chemical), Secondary (Biological) and Advanced treatments (RO).

Reverse Osmosis system of M/s ROCHEM, Mumbai with capacity of $50 \mathrm{~m}^{3}$ is installed in the unit. The system consists of pump to RO, Pre-filter, Sand filter, Pump, Cartridge filter, Pump and membrane module. Suspended particles, color and iron like impurities are removed by the filter system. A pressure of 60 bars is maintained in the membrane systems. The membrane module consist so three units. First unit consist of four modules and the rejects are passed to the second unit, which consists of two module. Third unit consists of one module. The final rejects of about $30 \%$ of the original inlet is collected into a tank and sent for solar evaporation. The collection of permeate was in the rate of $1450 \mathrm{l} / \mathrm{h}$ and the reject is 650 $1 /$ min. Wastewaters were collected from inlet to holding tank, inlet to aeration tank, out let of final clarifier i.e. holding tank, RO permeate and Rejects and subject to analysis.

\subsubsection{M/s Jaibharath Tanners, Ambur}

$\mathrm{M} / \mathrm{s}$ Jaibharath Tanners carries both the semi finish and finished leather with production capacity of $1.7 \mathrm{t} / \mathrm{d}$. Splitting, shaving, re-chroming, neutralization and dyeing generate $28 \mathrm{~m}^{3}$ of wastewater per day. The wastewaters from various units are stored in a sump. Then the effluent is pumped to anaerobic lagoon for removal of organics. The detention time is around 60 days. Then the effluent is sent to aerobic tank. Both mechanical and diffused aerators are provided. The effluents are sent to secondary settling tank for removal of suspended solids. The effluent coming out of secondary clarifiers is treated with alum to remove suspended solids and phosphates. The supernatant solutions are sent to RO units after sand filtration.

Reverse Osmosis system with capacity of $50 \mathrm{~m}^{3}$ is installed for recovery of $75 \%$ permeate. The system consists of pump to RO, Pre-filter, Cartridge filter, Pump and membrane module. The Rejects are allowed for solar evaporation and permeates are used back in the tanning process.

\subsubsection{M/s N.M.Zackariah \& Co, Ambur}

M/s N.M.Zackariah \& Co carries both semi finish and finished leather products of about 3.5 tons with wastewater generation of about 75 KLD. The effluents from Soaking and Tanning are sent for solar evaporation and recovery, respectively. The effluents from other sources are screened and allowed for settling. Then waste water treated by chemical flocculation using lime and alum, anaerobic lagoon and biological oxidation in aeration tank.

RO plant with capacity of 70 KLD and $70 \%$ recovery is installed and in operation. Permeate is used in the industrial operation and Reject is allowed for solar evaporation. Water samples were collected in all the stages of treatment are subject to analysis.

\subsubsection{Habeeb Taj Tanning Company, Gudiyattam}

Habeeb Taj tanning company deals with finishing of leather from raw skin. Soaking, liming, de-liming, pick- 
ling, tanning, shaving, re-chroming, dyeing and trimming are the processes involved with production capacity of $1.6 \mathrm{t} / \mathrm{d}$ and with wastewater generation of $50 \mathrm{~m}^{3}$. Soaking effluents are allowed for solar evaporation and spent chromium effluents are subject to chrome recovery system. The other units wastewaters generated are allowed for screening, chemical coagulation, anaerobic treatment and aeration. The final clarified effluent is sent to sand filters and RO unit with capacity of $75 \mathrm{~m}^{3}$. The rejects are sent for solar evaporation.

\subsubsection{Waste Water Sampling for Analysis}

Eight hourly composite sampling have been carried out after and before treatments of conventional methods and advanced RO technology. The samples were analyzed in mobile as well as stationary laboratories as per the prescribed standard methods $[13,14]$. Total chromium was measured using Atomic Absorption Spectrophotometer (AAS). All the chemicals used were of Analytical Grade. Duplicate analyses were carried out and the average values are presented.

\section{Results and Discussion}

The wastewater streams are segregated to three types such as highly toxic chromium containing wastewater, high BOD and COD containing wastewater and high inorganic salts containing waste water. After Chromium recovery, the waste water with chromium level in all the untreated effluents were in the range of $19.6 \mathrm{mg} / \mathrm{L}$ to $190.2 \mathrm{mg} / \mathrm{L}$. The total $\mathrm{Cr}$ value for M/s Eastern Chrome Tanning Corporation is 52.04 (Table $\mathbf{1}$ ), for $\mathrm{M} / \mathrm{s} \mathrm{T}$. Abdul Wahid Tanneries Ltd, 'C' Unit is, $92.64 \mathrm{mg} / \mathrm{L}$ (Table 2), M/s Jaibharath Tanners is $19.6 \mathrm{mg} / \mathrm{L}$ (Table 3), M/s N.M. Zackariah \& Co is $190.2 \mathrm{mg} / \mathrm{L}$ (Table 4) and M/s Habeeb Taj Co is $26.35 \mathrm{mg} / \mathrm{L}$ (Table 5); however it is significantly reduced after the conventional treatment. The schematic diagram of effluent treatment followed in the studied units is presented in the Figure 1.

\subsection{Conventional Treatment Methods}

Characteristics of wastewaters of the tanneries M/s Eastern Chrome Tanners and M/s T.Abdul Wahid which are following clari-flocculation with activated sludge process as conventional treatments and RO membrane as advanced treatments are presented in the Table $\mathbf{1}$ and Table 2 , respectively. The initial $\mathrm{pHs}$ of the tanneries are acidic due to use of mineral acids in the process. Lime and chemical coagulants have been added to raise the alkalinity and better flocculation effects. Chemical coagulation has removed $75-80 \%$ BOD followed by the biological oxidation i.e. activated sludge process has reduced $93-97 \%$ BOD. Significant removals of suspended solids and chemical oxygen demand have been attributed

Table 1. Characteristics of effluents from Eastern Chrome Tanning Corporation, Ambur.

\begin{tabular}{|c|c|c|c|c|c|}
\hline Parameters & Untreated wastewater & $\begin{array}{l}\text { After chemical } \\
\text { coagulation }\end{array}$ & $\begin{array}{l}\text { After Biological } \\
\text { treatment/RO Feed }\end{array}$ & RO Permeate & RO Reject \\
\hline $\mathrm{pH}$ & 4.6 & 7.6 & 8.3 & 7.0 & 7.2 \\
\hline Electrical Conductivity, $\mathrm{mS} / \mathrm{cm}$ & 9.30 & 8.10 & 7.96 & 0.51 & 13.94 \\
\hline $\mathrm{TDS}, \mathrm{mg} / \mathrm{L}$ & 7610 & 5795 & 5567 & 266 & 11636 \\
\hline $\mathrm{TSS}, \mathrm{mg} / \mathrm{L}$ & 910 & 200 & 113 & BDL & 154 \\
\hline $\mathrm{BOD}, \mathrm{mg} / \mathrm{L}$ & 2375 & 475 & 72 & BDL & 96 \\
\hline $\mathrm{COD}, \mathrm{mg} / \mathrm{L}$ & 5659 & 1226 & 300 & 19 & 623 \\
\hline Total Hardness as $\mathrm{CaCO}_{3}, \mathrm{mg} / \mathrm{L}$ & 1120 & 940 & 920 & BDL & 2580 \\
\hline Calcium Hardness as $\mathrm{CaCO}_{3}, \mathrm{mg} / \mathrm{L}$ & 760 & 860 & 840 & BDL & 1380 \\
\hline Sodium, mg/L & 1880 & 1720 & 1560 & 52 & 2840 \\
\hline Potassium, mg/L & 36 & 42 & 40 & 2 & 60 \\
\hline Chloride, $\mathrm{mg} / \mathrm{L}$ & 1531 & 1666 & 1576 & 84 & 2980 \\
\hline Sulphide, mg/L & 2.2 & - & 0.3 & - & - \\
\hline Sulphate, $\mathrm{mg} / \mathrm{L}$ & 3604 & 2318 & 2318 & 51 & 4341 \\
\hline Total Cr, mg/L & 52.04 & - & BDL & - & - \\
\hline
\end{tabular}

Note: '-’ Not Analyzed, 'BDL' Below Detection Limit. 
Table 2. Characteristics of effluents from T. Abdul Wahid Tanneries Ltd, ‘C’ Unit Ambur.

\begin{tabular}{|c|c|c|c|c|c|}
\hline Parameters & Untreated wastewater & $\begin{array}{l}\text { After chemical } \\
\text { coagulation }\end{array}$ & $\begin{array}{l}\text { After Biological } \\
\text { treatment/RO Feed }\end{array}$ & RO Permeate & RO Reject \\
\hline $\mathrm{pH}$ & 4.2 & 8.1 & 7.8 & 7.4 & 7.7 \\
\hline Electrical Conductivity, $\mathrm{mS} / \mathrm{cm}$ & 10.9 & 10.0 & 9.9 & 0.14 & 29.0 \\
\hline $\mathrm{TDS}, \mathrm{mg} / \mathrm{L}$ & 7200 & 6838 & 6708 & 128 & 20115 \\
\hline $\mathrm{TSS}, \mathrm{mg} / \mathrm{L}$ & 1460 & 180 & 116 & BDL & 264 \\
\hline $\mathrm{BOD}, \mathrm{mg} / \mathrm{L}$ & 3600 & 880 & 260 & $\mathrm{BDL}$ & 850 \\
\hline $\mathrm{COD}, \mathrm{mg} / \mathrm{L}$ & 7546 & 2075 & 943 & $\mathrm{BDL}$ & 2641 \\
\hline Total Hardness as $\mathrm{CaCO}_{3}, \mathrm{mg} / \mathrm{L}$ & 900 & 760 & 680 & $\mathrm{BDL}$ & 1960 \\
\hline Calcium Hardness as $\mathrm{CaCO}_{3}, \mathrm{mg} / \mathrm{L}$ & 520 & 580 & 400 & $\mathrm{BDL}$ & 1720 \\
\hline Sodium, $\mathrm{mg} / \mathrm{L}$ & 2200 & 1400 & 2120 & 28 & 5400 \\
\hline Potassium, mg/L & 20 & 16 & 18 & 2.4 & 50 \\
\hline Chloride, mg/L & 1215 & 1351 & 1396 & 40 & 4097 \\
\hline Sulphide, $\mathrm{mg} / \mathrm{L}$ & 1.0 & - & 0.3 & - & - \\
\hline Sulphate, $\mathrm{mg} / \mathrm{L}$ & 2842 & 2074 & 3318 & $\mathrm{BDL}$ & 7663 \\
\hline Total Cr, mg/L & 92.64 & - & $\mathrm{BDL}$ & - & - \\
\hline
\end{tabular}

Note: '-' Not Analyzed, 'BDL’ Below Detection Limit.

Table 3. Characteristics of effluents from Jaibharath Tanners, Ambur.

\begin{tabular}{|c|c|c|c|c|c|c|}
\hline Parameters & Untreated wastewater & $\begin{array}{c}\text { After Anaerobic } \\
\text { Lagoon }\end{array}$ & After aeration & RO Feed & RO Permeate & RO Reject \\
\hline $\mathrm{pH}$ & 4.0 & 8.0 & 8.3 & 8.0 & 7.0 & 7.4 \\
\hline Electrical Conductivity, $\mathrm{mS} / \mathrm{cm}$ & 6.0 & 5.9 & 5.6 & 5.6 & 0.14 & 18.6 \\
\hline TDS, mg/L & 4200 & 3996 & 4150 & 3913 & 118 & 16553 \\
\hline $\mathrm{TSS}, \mathrm{mg} / \mathrm{L}$ & 280 & 130 & 43 & 33 & & 110 \\
\hline $\mathrm{BOD}, \mathrm{mg} / \mathrm{L}$ & 680 & 500 & 140 & 104 & BDL & 390 \\
\hline $\mathrm{COD}, \mathrm{mg} / \mathrm{L}$ & 1698 & 1320 & 472 & 377 & 9 & 1509 \\
\hline Total Hardness as $\mathrm{CaCO}_{3}, \mathrm{mg} / \mathrm{L}$ & 380 & 380 & 320 & 280 & $\mathrm{BDL}$ & 1100 \\
\hline Sodium, mg/L & 960 & 340 & 1220 & 1280 & 32 & 4200 \\
\hline Potassium, mg/L & 21 & 27 & 54 & 54 & 1.2 & 160 \\
\hline Chloride, $\mathrm{mg} / \mathrm{L}$ & 720 & 720 & 675 & 675 & 64 & 3197 \\
\hline Sulphide, mg/L & 0.5 & - & - & 0.5 & - & - \\
\hline Sulphate, $\mathrm{mg} / \mathrm{L}$ & 582 & 748 & 1387 & 1689 & 20 & 5712 \\
\hline Total $\mathrm{Cr}, \mathrm{mg} / \mathrm{L}$ & 19.6 & - & 2.2 & - & - & - \\
\hline
\end{tabular}

Note: ‘-’ Not Analyzed, 'BDL’ Below Detection Limit. 
Table 4. Characteristics of effluents from M/s N.M. Zackariah \& Co, Ambur.

\begin{tabular}{|c|c|c|c|c|c|c|}
\hline Parameters & $\begin{array}{l}\text { Untreated } \\
\text { wastewater }\end{array}$ & $\begin{array}{l}\text { Outlet of Primary } \\
\text { Clarifier }\end{array}$ & $\begin{array}{c}\text { Outlet of } \\
\text { Anaerobic Lagoon }\end{array}$ & $\begin{array}{c}\text { Outlet of secondary } \\
\text { clarifier }\end{array}$ & RO Permeate & RO Reject \\
\hline $\mathrm{pH}$ & 4.6 & 8.6 & 8.3 & 7.0 & 6.9 & 6.8 \\
\hline Electrical Conductivity, $\mathrm{mS} / \mathrm{cm}$ & 15.9 & 12.4 & 11.7 & 11.0 & 0.74 & 41.5 \\
\hline $\mathrm{TDS}, \mathrm{mg} / \mathrm{L}$ & 14500 & 10488 & 8873 & 7966 & 438 & 26278 \\
\hline $\mathrm{TSS}, \mathrm{mg} / \mathrm{L}$ & 985 & 125 & 50 & 60 & BDL & 90 \\
\hline $\mathrm{BOD}, \mathrm{mg} / \mathrm{L}$ & 2700 & 850 & 680 & 30 & BDL & 104 \\
\hline $\mathrm{COD}, \mathrm{mg} / \mathrm{L}$ & 6102 & 2264 & 1839 & 226 & BDL & 765 \\
\hline Total Hardness as $\mathrm{CaCO}_{3}, \mathrm{mg} / \mathrm{L}$ & 1100 & 1240 & 680 & 550 & 2 & 480 \\
\hline Calcium Hardness as $\mathrm{CaCO}_{3}, \mathrm{mg} / \mathrm{L}$ & 760 & 1100 & 620 & 480 & 2 & 360 \\
\hline Sodium, mg/L & 3960 & 2560 & 2480 & 2280 & 76 & 5640 \\
\hline Potassium, mg/L & 62 & 39 & 35 & 34 & 2 & 61 \\
\hline Chloride, $\mathrm{mg} / \mathrm{L}$ & 1846 & 1800 & 2161 & 1711 & 80 & 6978 \\
\hline Sulphide, $\mathrm{mg} / \mathrm{L}$ & 1.6 & - & - & - & - & - \\
\hline Sulphate, $\mathrm{mg} / \mathrm{L}$ & 4624 & 3672 & 3735 & 3657 & 10 & 7140 \\
\hline Total Cr, mg/L & 190.20 & - & - & 0.06 & - & - \\
\hline
\end{tabular}

Note: ‘-’ Not Analyzed, 'BDL’ Below Detection Limit.

Table 5. Characteristics of effluents from M/s Habeeb Taj Co, Gudiyattam.

\begin{tabular}{|c|c|c|c|c|c|}
\hline Parameters & Untreated wastewater & $\begin{array}{l}\text { After Anaerobic } \\
\text { Lagoon }\end{array}$ & After aeration/RO Feed & RO Permeate & RO Reject \\
\hline $\mathrm{pH}$ & 4.6 & 9.1 & 7.0 & 7.0 & 7.0 \\
\hline Electrical Conductivity & 6.8 & 5.9 & 5.7 & 0.47 & 37.5 \\
\hline TDS & 4876 & 3642 & 3769 & 347 & 25434 \\
\hline TSS & 394 & 58 & 19 & BDL & 54 \\
\hline BOD & 1140 & 320 & 55 & BDL & 600 \\
\hline COD & 2830 & 849 & 302 & BDL & 2075 \\
\hline Total Hardness as $\mathrm{CaCO}_{3}, \mathrm{mg} / \mathrm{L}$ & 628 & 392 & 156 & BDL & 2274 \\
\hline Calcium Hardness as $\mathrm{CaCO}_{3}, \mathrm{mg} / \mathrm{L}$ & 392 & 140 & 98 & $\mathrm{BDL}$ & 2274 \\
\hline Sodium, mg/L & 1040 & 1000 & 1040 & 84 & 1720 \\
\hline Potassium, mg/L & 16 & 18 & 18 & 1.6 & 128 \\
\hline Chloride, $\mathrm{mg} / \mathrm{L}$ & 1200 & 1157 & 1157 & 100 & 7714 \\
\hline Sulphide, $\mathrm{mg} / \mathrm{L}$ & 2.3 & - & 0.3 & - & - \\
\hline Sulphate, $\mathrm{mg} / \mathrm{L}$ & 1705 & 373 & 567 & $\mathrm{BDL}$ & 2940 \\
\hline Total Cr, mg/L & 26.35 & - & BDL & - & - \\
\hline
\end{tabular}

Note: ‘-' Not Analyzed, 'BDL’ Below Detection Limit. 


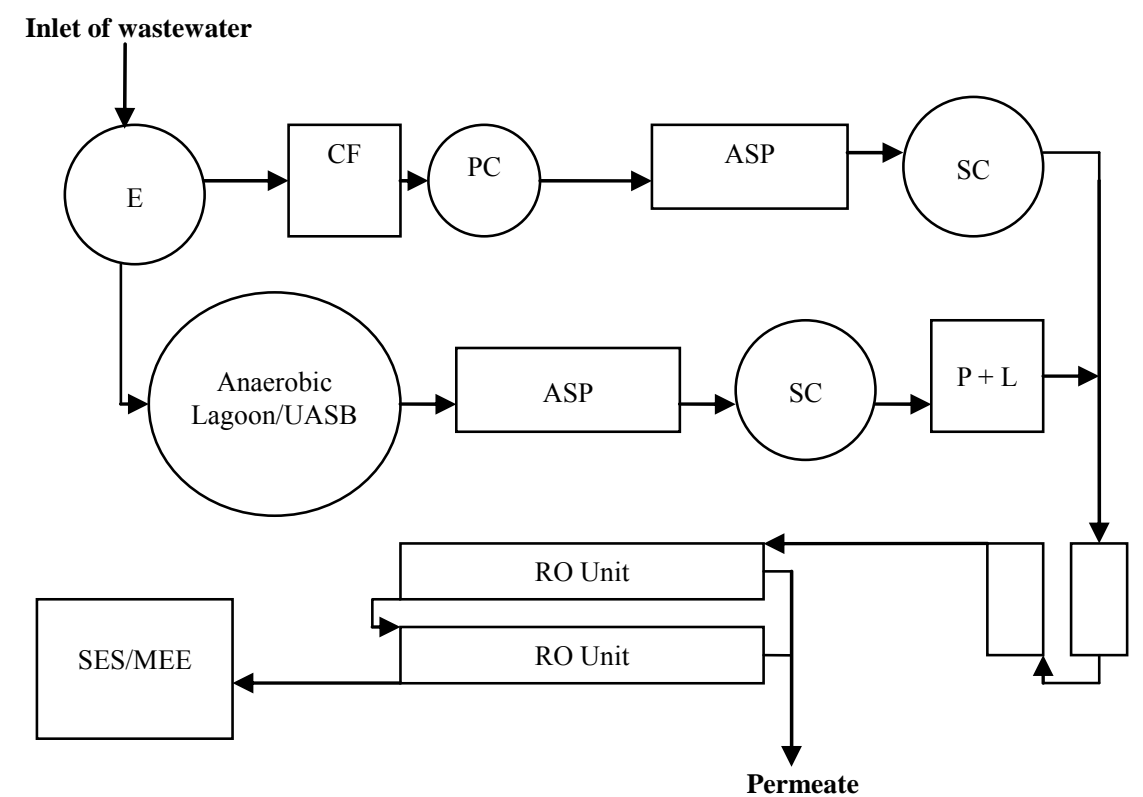

Figure 1. Schematic diagram of integrated wastewater treatment systems in tanneries for zero discharge. (E, Equalization Tank; CF, Clariflocculation; PC, Primary Clarifier; ASP, Activated Sludge Process; SC, Secondary Clarifier; UASB, Up-Flow Anaerobic Sludge Blanket; P + L, Polyelectrolyte and Lime Treatment; SES, Solar Evaporation System; MEE, Multiple Evaporation Evaporation).

due to flocculation. There is no considerable change in removal of soluble inorganic constituents that observed to be only $0-32 \%$ for TDS, hardness, chloride, sodium and sulphate. Due to formation of sparingly soluble calcium sulphate, the level of sulphate was reduced. Complete removal of chromium and $70-86.4 \%$ removal of sulphide have been observed by the combined chemical and biological treatments. Other industries such as N.M Zakaraiah and Habeeb are the units following anaerobic lagoon where at a long storage the organics are converted to methane and $\mathrm{H}_{2} \mathrm{~S}$. Anaerobic treatment and polishing with lime and polyelectrolyte has further reduced BOD. Total dissolved inorganic salts removal are negligible by the conventional treatments. The main objective of conventional methods is to enhance the life of $\mathrm{RO}$ and to reduce the cost of the treatment. The toxic pollutants such as chromium and sulphide were significantly removed by the conventional methods; precipitation and oxidation.

\subsection{Reverse Osmosis Membrane Technology}

In addition to the conventional treatments the RO membrane systems are equipped to remove dissolved solids. The permeates of these RO treatment systems are more than $70-85 \%$ recovery and the rejects are $15-30 \%$. BOD in the final permeate was observed to be below detection limit. TDS, one of the important parameter for performance of RO was found to be in the range of 3769-8060 $\mathrm{mg} / \mathrm{L}$ (average $5530 \mathrm{mg} / \mathrm{L}$ ) in the feed water and in the range of $118-438 \mathrm{mg} / \mathrm{L}$ (average $259 \mathrm{mg} / \mathrm{L}$ ) in the per- meate, which are well with in the drinking water standard. Rejects are generally containing more TDS i.e. 20,000 $\mathrm{mg} / \mathrm{L}$. They may also be processed further by installation of more RO units before subjecting to Evaporation System such as MEE to reduce the cost of MEE operation. Solar evaporation is a cheap technology and the evaporation rate in the area is $4 \mathrm{~mm}$ per day. Stringent precautionary measures have to be taken to avoid ground water percolation. Organic pollutants of tannery effluent will cause rapid scaling and befouling to the RO membrane and consequently reduction in flux rate and performance. They would also enhance the maintenance cost of the technology. Recently RO membrane combined with Membrane bioreactor (MBR) has successfully been used for treatment of mixed tannery effluents. RO treatment reduced the salt content of the MBR permeate by up to 91.1\% [15]. Comparisons of efficiency of the conventional methods and advanced methods are depicted in the Figure 2. Conventional methods are effective in removal of organics and advanced membrane process is effective in removal of dissolved solids in the effluent.

\subsection{Cost Analysis}

Any wastewater treatment system offered should be low cost in the developing countries like India. The installation and commissioning cost of conventional effluent treatment plant and RO plant is in the range of INR 100-150 lacs for tanneries. The maintenance and operation cost is as below: 


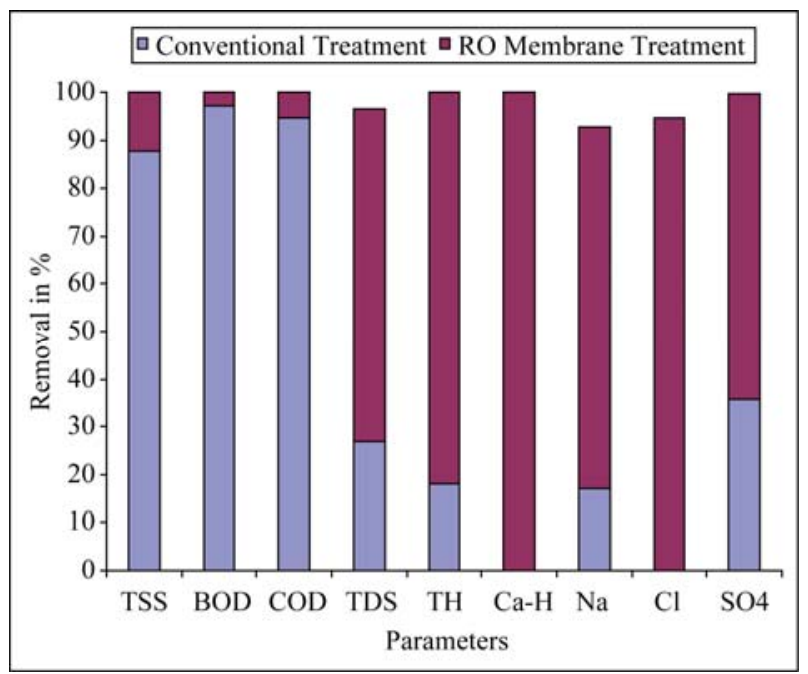

(a)

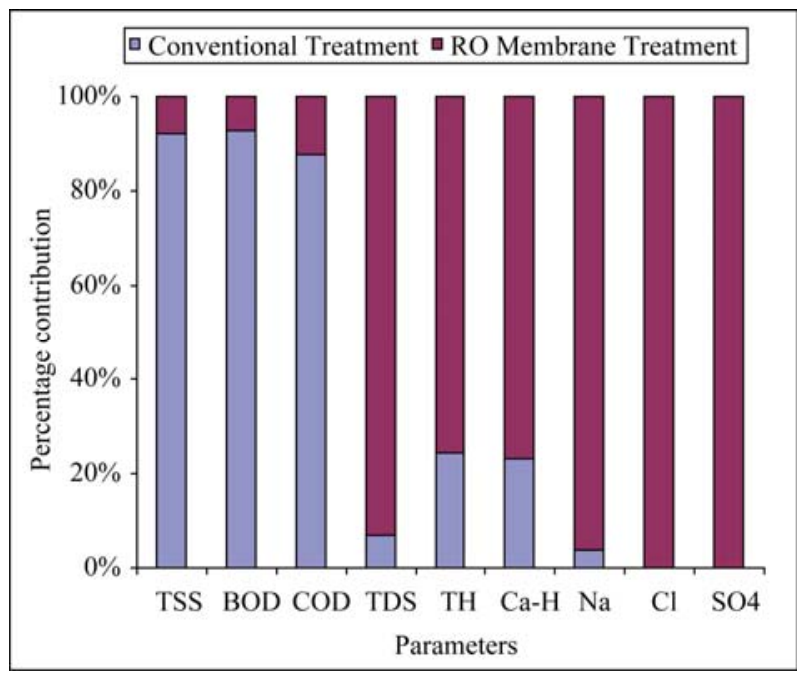

(b)

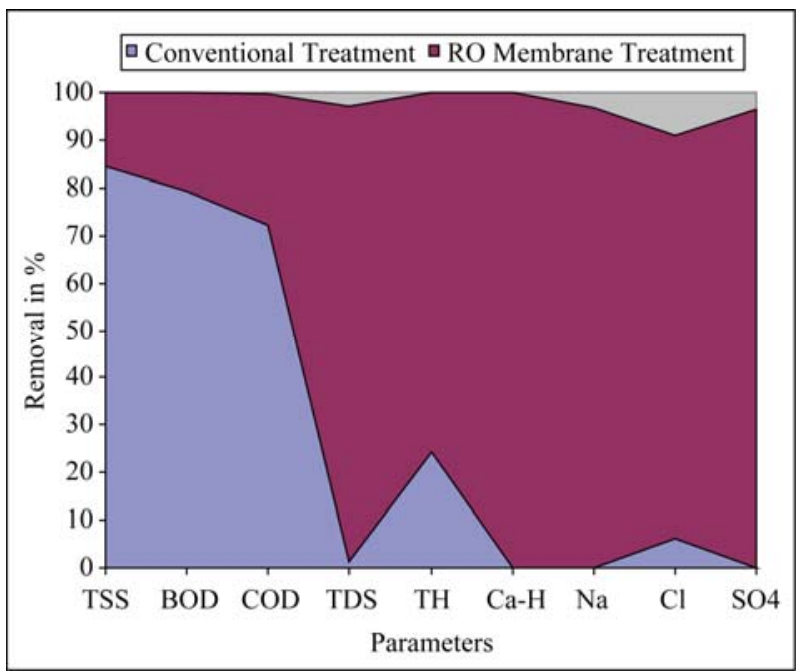

(c)

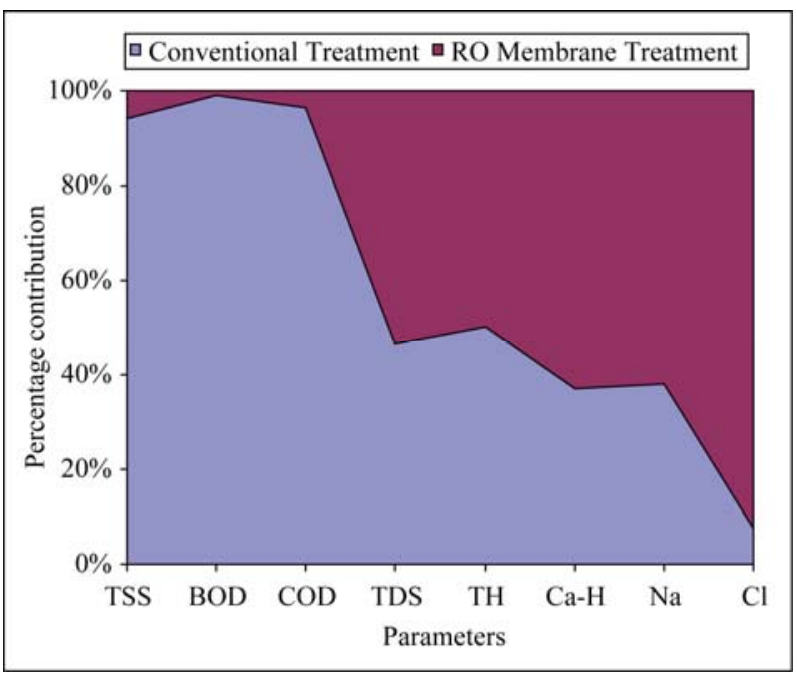

(d)

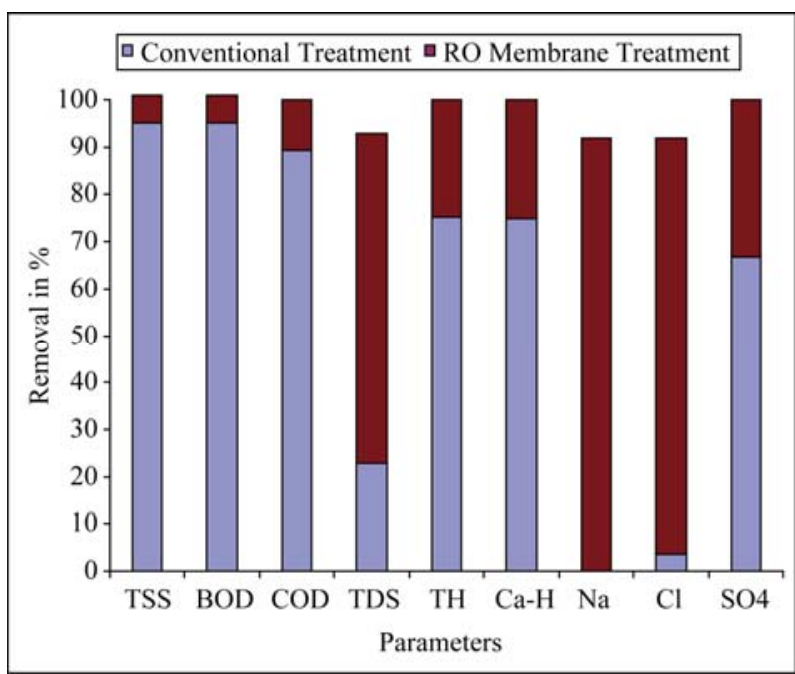

(e)

Figure 2. Comparison of efficiency of conventional methods and advanced methods. (a) M/s Eastern Chrome Tanning Corporation; (b) M/s T. Abdul Wahid Tanneries Ltd, 'C'; (c) M/s Jaibharath Tanners; (d) M/s N.M. Zackariah \& Co; (e) M/s Habeeb Taj Co.
Chemical cost

Power cost

Sludge handling

Manpower

Filters and cartridges (spares)

$\mathrm{RO} / \mathrm{NF}$ membrane maintenance
INR $8-10 \mathrm{~m}^{-3}$ INR $3-4 \mathrm{~m}^{-3}$ INR $1-2 \mathrm{~m}^{-3}$ INR $2-3 \mathrm{~m}^{-3}$ INR $6-12 \mathrm{~m}^{-3}$ INR $20-25 \mathrm{~m}^{-3}$
Principal and interest paid on the loan INR $40-50 \mathrm{~m}^{-3}$

The cost of wastewater treatment for operation and maintenances of RO including the pre-treatments (conventional methods) is INR $100-110 \mathrm{~m}^{-3}$ as against the water cost of INR $30-40 \mathrm{~m}^{-3}$. The principal cost including interest is about INR $40-50 \mathrm{~m}^{-3}$. The wastewater treat- 
ment is costlier than water cost. The multiple evaporation system cost is about INR $60-70 \mathrm{~m}^{-3}$ of reject. A common MEE facility may be cheaper than the individual one. Irrespective of the cost of wastewater treatment, the recycling process benefits by protecting environment from contamination and ground water table reduction.

\subsection{Other Cleaner Technology (CT) Options Recommended for Tanning Process}

1) Replacement of common salt preservation using enzyme and cold preservation technologies before bringing to tannery that may reduce the TDS as well as water consumption.

2) Soaking water in the last tanks may be used in the first tank to minimize water consumption.

3) Applying paddles with drums and adopting low float processing could minimize the use of water.

4) Washing in closed drums instead of rinsing with running water and prevention of wastage of water from pipes or hoses etc., may be followed for reducing wastewater.

5) Attempts shall be made for de-liming with carbon dioxide instead of ammonium salts.

6) Reduction in consumption of lime and quality of lime shall be improved to minimize pollution load in the wastewater.

\section{Conclusions}

The effluents of tanneries are segregated as high TDS soaking wastewater, toxic chromium wastewater and other wastewaters channels. After chromium recovery the wastewater is mixed with other wastewater and provided advanced treatment for water recycling. Higher organic load in the effluents are reduced before feeding into the RO system to avoid scale formation and befouling of the membranes. The studied tanneries show that the removal of total dissolved solids, sodium and chloride are in the range of $91-99 \%$. Seventy to eighty five percentage of wastewater has been recovered and recycled in the industrial operations. The rejects are evaporated under solar evaporation system or Multiple Effect Evaporation (MEE) technology and the solid wastes are disposed into a secured land fill site. The MEE is costlier technology as it consumes more thermal energy. RO system combined with conventional treatment is technically feasible.

\section{Acknowledgements}

The authors are thankful to the competent authority of Central Pollution Control Board (CPCB) for their keen encouragement to carry out the study. Also the laboratory staffs of Central Pollution Control Board, Bangalore are acknowledged for their kind assistance and co-operation in analysis.

\section{REFERENCES}

[1] T. S. Ramasami, S. Rajamani and J. R. Rao, "Pollution Control in Leather Industry: Emerging Technical Options," Central Leather Research Institute, Adyar, Madras, 1995.

[2] A. S. Naidu, "Indian Leather Industry in $21^{\text {st }}$ Century: Challenges and Opportunities," Yojana, 13 ${ }^{\text {th }}$ March, 2000.

[3] R. Krishnaswamy and G. Haridas, "Ground Water Pollution by Tanneries in Tamil Nadu (India)," In: W. Van Duijvenbooden, P. Glasbergen and H. Van Lelyveld, Eds., Proceedings of International Symposium on Quality of Ground Water, Noordwijkerhout, the Netherlands, 1981, pp 287-290. doi:10.1016/S0166-1116(08)71917-4

[4] C. P. Gupta, M. Thangarajan, V. V. S. Gurunadha Rao, M. Ramachandra and M. R. K. Sarma, "Preliminary Study of Ground Water Pollution in the Upper Palar Basin and Feasibility of Mass Transport Modeling to Predict Pollutant Migration," National Geophysical Research Institute (NGRI) Tech Report, No. 94-GW-168, 1994, pp 45.

[5] V. V. S. Gurunadha Rao and M. Thangarajan, "Ground Water Pollution Due to Discharge of Tannery Effluents in Upper Palar Basin, Tamil Nadu, India: An Assessment through Mass Transport Modeling," Environmental Engg and Policy, Vol. 1, No. 4, 1999, pp 201-208. doi:10.1007/s100220050023

[6] V. Tare, S. Gupta and P. Bose, "Case Studies on Biological Treatment of Tannery Effluents in India," Air \& Waste Management Association, Vol. 53, 2003, pp. 976-982.

[7] Z. Song, C. J. Williams and R. G. J. Edyvean, "Tannery Wastewater Treatment Using an Up-Flow Anaerobic Fixed and Biofilm Reactor (UAFBR)," Environmental Engineering Science, Vol. 20, No. 6, 2003, 587-599. doi:10.1089/109287503770736104

[8] S. M. Contreras-Ramos, D. Alvarez-Bernal, TrujilloTapia and L. Dendooven, "Composting of Tannery Effluent with Cow Manure and Wheat Straw," Bioresource Technology, Vol. 94, No. 2, 2004, pp. 223-228.

[9] A. Hafez, M. S. E. Manharwwy and M. A. Khedr, "RO Membrane Removal of Unreacted Chromium from Spent Tanning Effluent. A Pilot Scale Study, Part 2," Desalination, Vol. 144, 2002, pp. 237-242. doi:10.1016/S0011-9164(02)00318-1

[10] A. Hafez and M. S. E. Manharwwy, "Design and Performance of Two-Stage/Two Pass RO Membrane System for Chromium Removal from Tannery Wastewater. Part 3," Desalination, Vol. 165, 2004, pp. 141-151.

[11] O. Lefebvre, N. Vasudevan, M. Torrijos, K. Thanasekaran and R. Moletta, "Halophilic Biological Treatment of Tannery Soak Liquor in a Sequencing Batch Reactor," Water Research, Vol. 39, No.8, 2005, pp. 1471-1480. doi:10.1016/j.watres.2004.12.038

[12] S. Rajamani, T. S. Ramasami, J. S. A. Langerwerf and J. E. Schappman, "Environmental Management in Tanneries-Feasible Chromium Recovery and Reuse System," In: International Conference on Appropriate Waste Management Technology for Developing Countries, Nagpur, India, 1995, pp. 965. 
[13] APHA, "Standard Methods for the Examination of Water and Wastewater," $20^{\text {th }}$ Ed., American Public Health Association, Washington DC, USA, India, 1998.

[14] CPCB, "Laboratory Manual for Analysis of Samples," Central Pollution Control Board, Delhi, 2001.
[15] W. G. Scholz, P. Rouge, A. Bodalo and U. Leitz, "Desalination of Mixed Tannery Effluent with Membrane Bioreactor and Reverse Osmosis Treatment," Environmental Science \& Technology, Vol. 39, No. 21, 2005, pp. 8505-8511. doi:10.1021/es050330p 